\title{
Concomitant Traumatic Coronary Artery Dissection and Tricuspid Valve Injury: A Case Report
}

\author{
Firas Yazigia, ${ }^{\mathrm{a}}$, Anuradha Kolluru ${ }^{\mathrm{a}}$
}

\begin{abstract}
Among the causes of death in all age groups, deaths due to trauma rank third after cardiovascular diseases and cancer. Until age 40 , chest trauma constitutes $20-25 \%$ of the causes of deaths due to trauma. Blunt cardiac trauma develops frequently following motor-vehicle accidents and its mortality rate is high. Of all types of cardiac injury that can result from blunt chest trauma, coronary artery dissection is the most infrequent one. The consequences of coronary artery dissections are variable, ranging from none or mild myocardial infarction to massive myocardial infarction or death. We report two unusual cardiac complications of blunt chest trauma: a traumatic dissection in both left anterior descending artery (LAD) and right coronary artery (RCA), concomitant with tricuspid insufficiency due to papillary muscle rupture. The management of the patient had to be tailored due to the complexity of the presentation. The final treatment plan resulted in uneventful clinical course and good overall medical results.
\end{abstract}

Keywords: Dissection; Blunt chest trauma; Papillary muscle rupture; Coronary artery

\section{Introduction}

Among the causes of death in all age groups, deaths due to trauma rank third after cardiovascular diseases and cancer [1]. Until age 40 , chest trauma constitutes $20-25 \%$ of the causes of deaths due to trauma [2]. Blunt cardiac trauma develops frequently following motor-vehicle accidents and its mortality rate is high. Due to a lack of standard diagnostic criteria, the incidence of blunt cardiac injury remains

Manuscript accepted for publication June 22, 2011

${ }^{\text {a} S t . ~ J o h n ~ H o s p i t a l ~ \& ~ M e d i c a l ~ C e n t e r, ~ D e t r o i t, ~ M I, ~ U S A ~}$

bCorresponding author: Firas Yazigi, Email: firas.yazigi@stjohn.org

doi:10.4021/jmc242w uncertain; the Centers for Disease Control and Prevention estimates 30000 cases per year in the United States. Electrocardiography and serum troponin measurement should be performed when blunt cardiac injury is suspected [3]. Echocardiography is the test of choice when the initial evaluation leads to a high clinical suspicion of blunt cardiac injury [4].

\section{Case Report}

We report a case of a 57 year-old taxi driver who was found unconscious and slumped behind the steering wheel of his car. Per police report, the driver was unrestrained, and there was no airbag deployment. The estimated speed of the vehicle at the time of the accident was about 50-60 miles per hour. The vehicle hit a steel utility pole at the side of the road at the time of the incident.

After regaining his consciousness, the victim reported no complaints prior to the accident, which was described as a sudden loss of consciousness with no alarming signs. There was a denial of any history of seizures or syncopal episodes in the past. The victim's past medical history included end stage renal disease on hemodialysis, and hypertension. He reported no current tobacco, alcohol, or drug use.

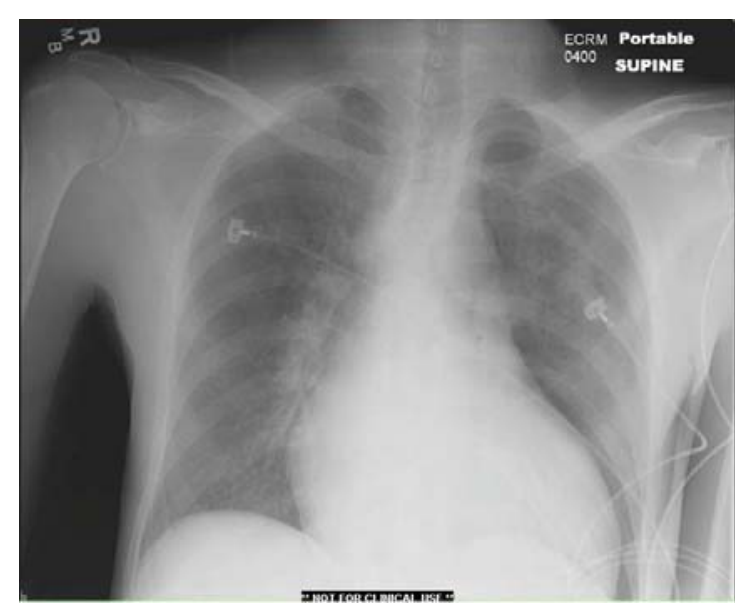

Figure 1. CXR on admission showing posterior left upper lobe atelectasis and small pneumothorax. 


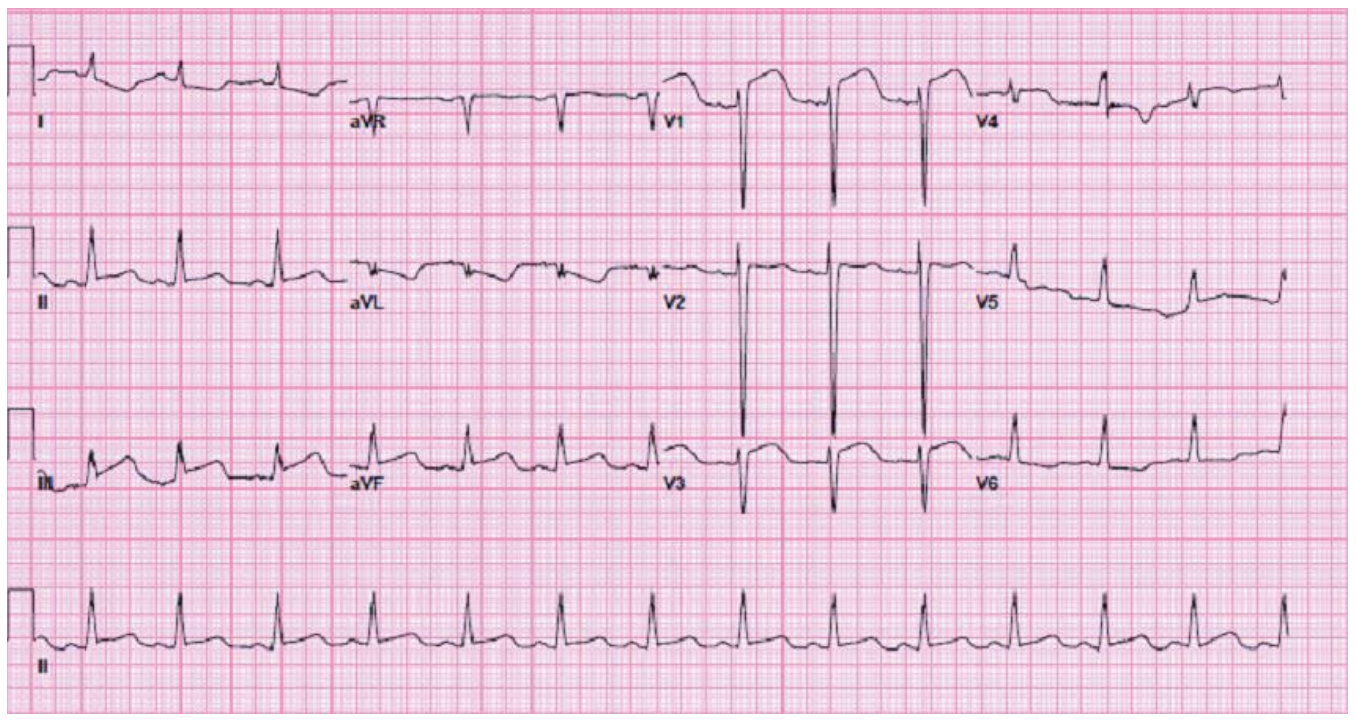

Figure 2. EKG findings were consistent with acute injury pattern in anterior and inferior leads.

The patient was transferred to the nearest trauma-ready medical facility and his vitals on arrival as reported by the trauma team were as the following: Temperature 97.8, Pulse 88, Blood Pressure 75/60, and oxygen saturation on room air of $98 \%$. His glascow coma scale was 15 , and blood glucose was 135 . His initial physical examination revealed pupils size of around $3 \mathrm{~mm}$ and positive reactivity to light. He suffered a deep chin laceration of around $5 \mathrm{~cm}$ in size. Ecchymosis was noted on the anterior chest wall. His cardiac examination was positive for a systolic murmur of 2/6 intensity best heard on the right sterna border.

The patient received an initial appropriate supportive care per the trauma team. Full panel of blood work was sent. Electrocardiogram and Chest $\mathrm{x}$-ray were ordered and the results showed in Figure 1 and 2.

After reviewing the results of the Chest x-ray and Elec-

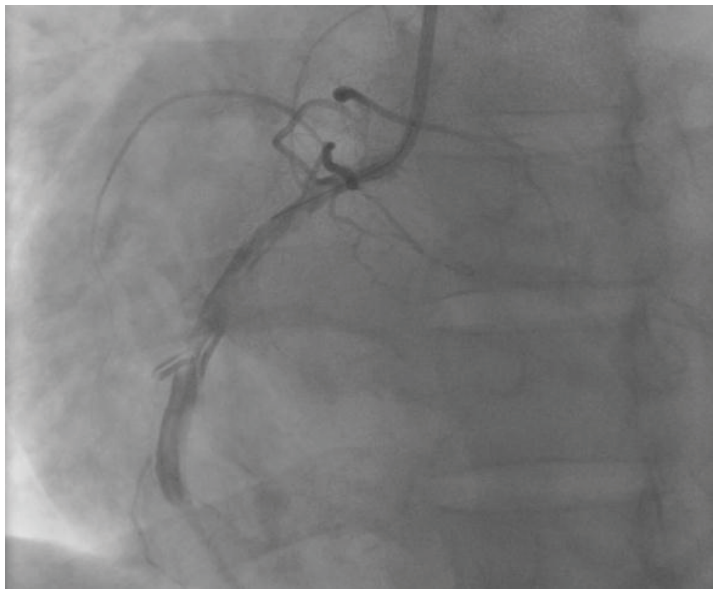

Figure 3. Coronary angiogram showing a dissection in mid right coronary artery. trocardiogram, and after discussion with cardiology service, the decision was made to transfer the patient to the catheterization lab for immediate evaluation of possible percutaneous coronary intervention (PCI) for ST-elevation myocardial infarction (STEMI). The patient was found to have a dissection of his right coronary artery (RCA) and left anterior descending artery (LAD). His left anterior descending artery lesion was managed with PCI and stent was placed. (Fig. 3, 4)

Upon arrival to the intensive care unit, a 2D-echocardiogram with Doppler was ordered to complete the evaluation, and the results came back positive for severe tricuspid regurgitation and flail anterior valve leaflet and possible papillary muscle rupture. (Fig. 5, 6)

The patient was managed medically thereafter with good response and he was discharged on the proper medication for

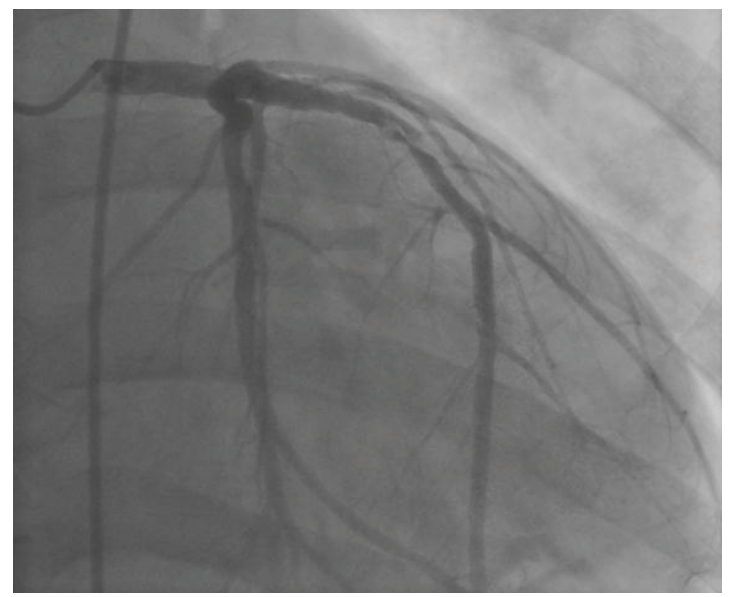

Figure 4. Coronary angiogram revealing a dissection in mid left anterior descending artery. 


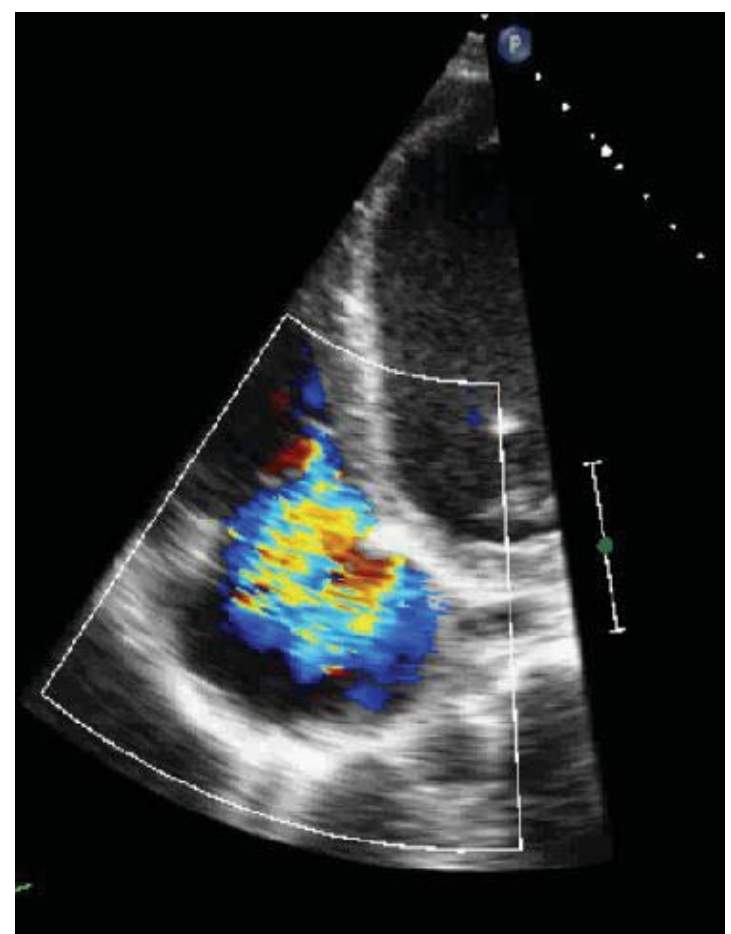

Figure 5. 2D-echocardiogram in apical 4-chamber view demonstrating wide-open tricuspid regurgitation.

his conditions to cardiac rehabilitation facility.

In summary, this was a rare presentation of concomitant coronary artery dissection and papillary muscle rupture following blunt chest trauma.

\section{Discussion}

With the recent increase in high speed motor vehicle accidents, blunt cardiac trauma is seen more frequently.

We report two unusual cardiac complications of blunt chest trauma: a traumatic dissection in both left anterior descending artery (LAD) and right coronary artery (RCA), concomitant with tricuspid insufficiency due to papillary muscle rupture.

Of all types of cardiac injury that can result from blunt chest trauma, coronary artery dissection is the most infrequent one. More common types of cardiac injury resulting from blunt chest trauma are myocardial contusion, septal or free cardiac wall rupture, pericardial laceration or rupture, hemopericardium with or without cardiac tamponade, ventricular aneurysm, valvular injury and cardiac arrhythmias [5].

The consequences of coronary artery dissections are variable, ranging from none or mild myocardial infarction to massive myocardial infarction or death [6].

The occurrence of an acute myocardial infarction after non-penetrating chest trauma is an extremely rare compli-

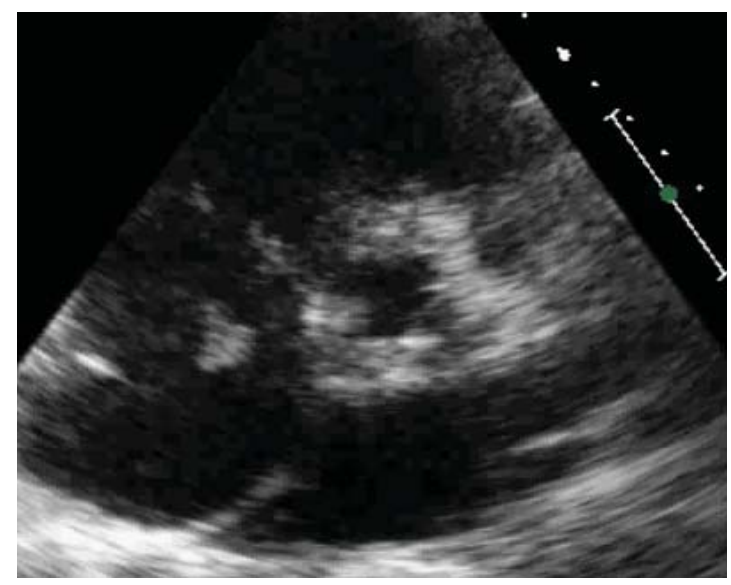

Figure 6. 2D-echocardiogram in parasternal short axis view demonstrating flail anterior leaflet of the tricuspid valve.

cation. Dissection of the coronary artery with subsequent thrombus formation is one of the possible pathophysiologic mechanisms of MI following blunt chest trauma [7].

In coronary artery dissection following blunt chest trauma, the left anterior descending coronary artery (LAD) is most often involved [8].

The treatment of patients with coronary artery dissection is generally dictated by the clinical course and is the same as in patients with coronary atherosclerosis [9].

In patients with ongoing ischemia despite optimal medical therapy, or involvement of the left main coronary artery or proximal left anterior descending artery (LAD), either angioplasty or coronary artery bypass surgery should be considered [10].

With regard to valvular injury, autopsy studies indicate that the aortic valve is most commonly involved, followed by the mitral and then tricuspid [11].

Valvular disruption is reported to be uncommon in patients presenting alive to the hospital. However, tricuspid valve injury may be under-diagnosed because the clinical manifestations are likely to be subtle [11].

The location of the right ventricle behind the sternum leaves it vulnerable to injury from anteroposterior compression. When a deceleration force is transmitted through the ventricle, especially during the end-diastolic phase, a regurgitant jet can initiate the rupture of a papillary muscle or of the chordae tendineae [12].

Alternatively, delayed valvular rupture may be due to papillary muscle contusion with hemorrhage, inflammation, and late necrosis, leading to disruption over time (13).

\section{Conclusion}

We present a very unusual case of dual coronary artery dissection resulting in acute myocardial infarction concomitant with tricuspid regurgitation due to papillary muscle rupture. The management of the patient had to be tailored due to the 
complexity of the presentation. The final treatment plan resulted in uneventful clinical course and good overall medical results.

\section{References}

1. Jones KW. Thoracic trauma. Surg Clin North Am. 1980;60(4):957-981.

2. Er M, Isik AF, Kurnaz M, Cobanoglu U, Sagay S, Yalcinkaya I. Clinical results of four hundred and twenty-four cases with chest trauma. Ulus Travma Acil Cerrahi Derg. 2003;9(4):267-274.

3. Elie MC. Blunt cardiac injury. Mt Sinai J Med. 2006;73(2):542-552.

4. Dounis G, Matsakas E, Poularas J, Papakonstantinou K, Kalogeromitros A, Karabinis A. Traumatic tricuspid insufficiency: a case report with a review of the literature. Eur J Emerg Med. 2002;9(3):258-261.

5. Vlay SC, Blumenthal DS, Shoback D, Fehir K, Bulkley BH. Delayed acute myocardial infarction after blunt chest trauma in a young woman. Am Heart J. 1980;100(6 Pt 1):907-916.

6. Malangoni MA, McHenry CR, Jacobs DG. Outcome of serious blunt cardiac injury. Surgery. 1994;116(4):628632; discussion 632-623.

7. Brasseur E, Ghuysen A, Mommens V, Janssen N,
Legrand V, D’Orio V. Coronary dissection and nonpenetrating chest trauma. Ann Cardiol Angeiol (Paris). 2006;55(4):233-239.

8. Pifarre R, Grieco J, Garibaldi A, Sullivan HJ, Montoya A, Bakhos M. Acute coronary artery occlusion secondary to blunt chest trauma. J Thorac Cardiovasc Surg. 1982;83(1):122-125.

9. DeMaio SJ, Jr., Kinsella SH, Silverman ME. Clinical course and long-term prognosis of spontaneous coronary artery dissection. Am J Cardiol. 1989;64(8):471-474.

10. Kerwin TC, Ruggie N, Klein LW. Spontaneous coronary artery dissection following low-intensity blunt chest trauma: a case report and review of current treatment options. J Invasive Cardiol. 2002;14(11):679-681.

11. Zakynthinos EG, Vassilakopoulos T, Routsi C, Roussos C, Zakynthinos S. Early- and late-onset atrioventricular valve rupture after blunt chest trauma: the usefulness of transesophageal echocardiography. J Trauma. 2002;52(5):990-996.

12. Lin SJ, Chen CW, Chou CJ, Liu KT, Su HM, Lin TH, Voon WC, et al. Traumatic tricuspid insufficiency with chordae tendinae rupture: a case report and literature review. Kaohsiung J Med Sci. 2006;22(12):626-629.

13. Kulik A, Al-Saigh M, Yelle JD, Rubens FD. Subacute tricuspid valve rupture after traumatic cardiac and pulmonary contusions. Ann Thorac Surg. 2006;81(3):1111-1112. 